\title{
Structural Differences in Some Psychological Characteristics between Young Men and Women
}

\author{
Dragan Popovic, Ankica Hosek, Evagelia Boli, Milos Popovic, Vladimir Savic, Jasna Popovic \\ Faculty of Sport and Physical Education, University of Pristina Temporarily Based in Leposavic, \\ Leposavic, Serbia \\ Email: dragan.popovic@pr.ac.rs
}

Received 28 May 2016; accepted 16 June 2016; published 20 June 2016

Copyright (C) 2016 by author and OALib.

This work is licensed under the Creative Commons Attribution International License (CC BY). http://creativecommons.org/licenses/by/4.0/

\section{(c) (i) Open Access}

\section{Abstract}

The aim of this study is to investigate whether there are structural differences between psychological spaces of men and women under the simplest possible model of analysis of these differences, i.e. based on comparing configurations of vectors of cognitive and conative functions. On a sample of 2664 participants (1332 males and 1332 females) aged 18 years who were described by three tests of the efficiency of cognitive processors, six tests of disorders of conative regulators, four tests of disorders of socialization process, a factor of the intensity of manifest aberrant behavior and academic achievement, structural differences between the sexes were analyzed using the methods of least squares, (maximum likelihood). These and many numerically smaller but still significant differences in the configurations of the analyzed variables show that it is almost absolutely certain that male and female participants of this age live in different psychological spaces, which is confirmed by the results of previously conducted analyses of structural differences in cognitive and conative spaces between men and women.

\section{Keywords}

Sexual Dimorphism, Cognitive Processors, Conative Regulators, Structural Differences

Subject Areas: Psychology, Sociology

\section{Introduction}

The results of several studies conducted in the last dozen years have shown that there are not only quantitative but also structural differences between psychological spaces of men and women.

In one of the first such studies [1], on a sample of 257 male and 184 female participants aged 15 to 20 years 
which was drawn from a population of high school students, three tests of cognitive functioning to evaluate the efficiency of perceptual, serial and parallel processors and nine conative tests to assess extraversion, psychosomatic disorders, anxiety, the most important modalities of aggressiveness, dissociation and disintegration of conative functions were used. The results were associated with four variables derived by a confirmatory method of factor analysis from the evaluation of 49 behavioral characteristics by which the degree of deviant, psychopathic and neurotic behavior as well as propensity to drug addiction was estimated. Differences between men and women in this age group were not only quantitative; women, contrary to the results of previous studies, had significantly more incoherent configuration of cognitive, conative and behavioral characteristics.

However, these results are obtained under a linear canonical model. As relations among conative characteristics and very likely relations among cognitive abilities assumed by cybernetic models of cognitive and conative functions are not linear, and not linear are relations between of cognitive and conative characteristics [1] and [2]; it can reasonably be assumed that the shortest distance between the centroid of the male population and centroid of the female population in cognitive and conative spaces is not a straight line and it is therefore pertinent to investigate what are the differences in cognitive abilities and conative characteristics between men and women under some nonlinear discriminant model. Accordingly, in a subsequent study [2], it is investigated what are the quantitative and structural differences between young men and women in cognitive and conative spaces under a simple nonlinear model of canonical discriminant analysis. Based on the same data as in the previous study, the results in all variables are transformed into fourth-order nonmonotonic splines so as to maximize the coefficient of separation between the sexes. Structural differences between men and women in this age group are found again: women have significantly more incoherent configuration of cognitive characteristics and somewhat greater coherence of conative characteristics, so women and men are actually in structurally different psychological spaces.

This is later confirmed by a very similar method in a study conducted on adult participants [3]. On representative samples of 666 women and 666 men aged 18 to 60 years, quantitative and structural differences in the dimensions of neuroticism, extraversion, openness, agreeableness, conscientiousness, amorality and rigidity between men and women are analyzed after transformation of the variables into fourth-order nonmonotonic splines so as to maximize the coefficient of separation between the sexes. Structural differences are again significant and actually greater than quantitative differences. This is mainly influenced by structural differences in relations among the factors of neuroticism, amorality, agreeableness and extraversion. The configuration of these factors clearly suggests that their psychological content is different in women and men.

The hypothesis that conative differences between men and women have a deeper physiological basis is the impetus for the research study conducted by [4]. The HI2 test constructed by Bosnar, Prot and Momirovic was applied to a sample of 360 participants (180 males and 180 females) aged 15 to 20 years so that from a set of 1470 indicators of various disorders of conative functions, a computer program chose a subset of 30 indicators of psychosomatic disorders which had the largest relationship with the hypothetical factor of psychogenic disorders of regulation and control of organic functions. And here, significant structural differences were also found; dispersion of results in the sample of young women was significantly higher than dispersion of results in the sample of young men. As these results were consistent with the results of earlier studies of sexual dimorphism in cognitive space, it was concluded that young men and women are also in different cognitive spaces when it comes to the segment of this space defined by the efficiency of the systems for regulation and control of organic functions.

The fact that there are subtle but significant structural differences between men and women was also confirmed by the analysis conducted by [5]. Two sets of 666 male and 666 female participants aged 18 years described by tests of efficiency of cognitive processors, conative regulators and the achieved level of socialization were classified using Lebart`s dual taxonomic neural network. In each set, the network identified three taxa, one of which consisted of participants with impaired functions of conative regulators, the other consisted of participants with impaired functions of cognitive processors, and the third of the cognitively and conatively normal participants. Although similarly defined taxa were obtained in both sets, they were still structurally different. In the female participants and the taxon of participants with disorders of conative functions, there were considerably more those with an abnormal level of activity, and in the taxon of participants with disorders of cognitive processors, there were much more those with defective functions of serial processor. In the similar taxon of male participants, there were a disproportionately high number of those with defective functions of parallel processor.

Structural differences between participants of different sexes were analyzed under another taxonomic model. 
Differences in distribution of some psychic disorders in populations of young men and women were analyzed on the basis of the data obtained through the tests that assessed cognitive and conative functions assumed by cybernetic models of cognitive and conative functioning, disorders of the socialization process and intensity of manifest symptoms of aberrant behavior on a random sample of 1334 participants (667 males and 667 females) aged 18 years. These participants were classified by means of iterative application of linear classifiers with very high recognition accuracy. This algorithm found that there was a set of almost $29 \%$ of cognitively and conatively normal participants with a somewhat higher level of activity and above average efficiency of parallel processor, a set of about $22 \%$ of very stupid participants, seemingly non-aggressive but with low efficiency of conative regulators, a set of nearly $16 \%$ of participants with antisocial personality disorders, or psychopaths, and a set consisting of over $32 \%$ of anxious neurotics who had above-average efficiency of cognitive processors and therefore above-average academic achievement. The distribution of male and female participants in these taxa was highly uneven. In the taxon of well socialized participants with above-average efficiency of all conative regulators, slightly higher levels of activity, average efficiency of perceptual and serial processors, but above average efficiency of parallel processor, that is, participants with efficient functions of predominantly biological cognitive processors and conative regulators, there were about $37 \%$ of men and $20 \%$ of women. In the taxon consisting of participants with inferior functions of cognitive processors and below-average efficiency of conative regulators and therefore lower levels of socialization, there were about $32 \%$ of female participants and only about $13 \%$ of male participants. In the third, psychopathic, taxon, there were about $26 \%$ of male and only slightly over $6 \%$ of female poorly socialized and aggressive participants who had distinct symptoms of aberrant behavior and low adaptation to school environment. In the fourth taxon consisting of above-average intelligent, but actually neurotic participants, there were almost $41 \%$ of women and almost $24 \%$ of men. Relations between the gender and belonging to taxa were significant, but they were not symmetrical, because based on the belonging to thus formed taxa, the gender of participants could be inferred two times better than based on the information on which gender the participant was, it could be predicted to which psychological type he or she belonged.

The fact that similar structural differences also exist in other segments of anthropological space was confirmed, among others, by the results of comparative analysis of relations between morphological characteristics and intellectual abilities of men and women aged 19 to 27 years [6]. The intensity of these relations was considerably higher in women and was determined primarily by harmonious body constitution, while in men, it was determined by stenomorphic body type.

The aim of this study was to investigate whether there are structural differences between psychological spaces of men and women under the simplest possible model of analysis of these differences, i.e. based on comparing configurations of vectors of cognitive and conative functions.

\section{Methods}

From the population of Serbia's high school students aged 18 years, two samples of 1332 male and 1332 female participants were drawn at random. A battery of measurement instruments was applied from whose results the variables presented in Table 1 were derived.

The instruments for assessing disorders of conative functions were designed under the cybernetic model described in [7] and [8]. The cybernetic model of cognitive functions under which instruments for assessing the efficiency of cognitive processors were constructed is described in [9] and [10]. The socialization test battery containing tests DELTAl, DELTA3, SlGMAl and SP5 was proposed by [11] [12], but in this study, the revised forms designed by Momirovic, Hosek and Dzamonja were applied. The STAT variable was introduced in order to assess possible ecosensitivity of cognitive and conative characteristics. The ABER variable formed from a set of 46 symptoms of aberrant behavior estimates the global intensity of manifest aberrant behavior. The ACAD variable is defined by the first semester grade point average in the year of the research.

All the variables are defined by ordinary summing the results in the test particles, except for the STAT variable defined as the first principal component of optimally scaled indicators of social status and ACAD variable defined as an ordered categorical variable.

The structural differences between male and female participants were analyzed based on the differences in configurations of the applied variables. For this purpose, the program COMPCOR2 [13] and [14], was used to compare two correlation matrices obtained by describing two independent samples of participants described on the same set of quantitative variables. The most important methods implemented in this program as well as in several programs written in the Genstat language are presented in [13] [14]. 
Table 1. Code designations, content and lower bounds for the reliability of variables.

\begin{tabular}{ccc}
\hline Code & Content & 6 \\
EPS & Activity regulation & 0.90 \\
CHI & Disorders of regulation of organic functions & 0.91 \\
ALPHA & Disorders of regulation of defense reactions & 0.93 \\
SIGMA & Disorders of regulation of attack reactions & 0.89 \\
DELTA & Disorders of coordination of regulatory functions & 0.94 \\
ETA & Disorders of integration of regulatory functions & 0.92 \\
DELTAl & Psychasthenic dissociation & 0.93 \\
DELTA3 & Regression dissociation & 0.83 \\
SIGMAl & Psychopathic aggressiveness & 0.88 \\
SP5 & Hysterical aggressiveness & 0.90 \\
ABER & Aberrant behavior & 0.91 \\
STAT & Passive social status & 0.56 \\
IP & Efficiency of perceptual processor & 0.96 \\
SP & Efficiency of serial processor & 0.97 \\
PP & Efficiency of parallel processor & 0.90 \\
ACAD & Academic achievement & $(0.44)$ \\
\hline
\end{tabular}

\section{Results}

The main results obtained by the applied method for analysis of structural differences are shown in the following Tables 2-5.

Accordingly, under all the applied tests, including very conservative tests constructed by Schoenemann, the configurations of variables in the samples of male and female participants differ significantly and substantially. The most important reasons for these differences are as follows:

1) In men, disorders of cortical control of the activating function of the reticular formation have considerably more influence on disorders of the system for regulation and control of defense reactions;

2) In women, disorders of cortical control of the activating function of the reticular formation have considerably more influence on disorders of the system for regulation and control of attack reactions;

3) In women, disorders of cortical control of the activating function of the reticular formation have considerably more influence on manifest aberrant behavior;

4) In men, disorders of the system for regulation and control of organic functions have considerably more influence on poor academic achievement;

5) In men, there is significantly larger relationship between dissociation caused by regression to onogenetically and phylogenetically passed developmental stages and hysterical aggressiveness;

6) Low efficiency of the functions of parallel processor has considerably greater influence on poor academic achievement in women than in men.

Of course, on such large samples of participants, many numerically smaller differences are also significant, but they are of much less importance. However, in general, differences in configurations of the analyzed variables are so numerous and such that it is almost completely certain that male and female participants of this age live in different psychological spaces.

\section{Discussion}

Based on the findings of neurophysiological studies of differences in the organization of cerebral functions of men and women ([1]-[7] [15]-[20]; etc), this study was, in fact, expected to yield these results. Those research 
D. Popovic et al.

Table 2. Intercorrelations of variables in the sample of male participants.

\begin{tabular}{|c|c|c|c|c|c|c|c|c|}
\hline Code & EPSM & CHIM & ALPHAM & SIGMAM & DELTAM & ETAM & DELTA1M & DELTA3M \\
\hline EPSM & 1.000 & -0.113 & -0.129 & 0.179 & -0.107 & -0.069 & -0.106 & 0.055 \\
\hline CHIM & -0.113 & 1.000 & 0.716 & 0.435 & 0.675 & 0.717 & 0.670 & 0.571 \\
\hline ALPHAM & -0.129 & 0.716 & 1.000 & 0.440 & 0.611 & 0.733 & 0.695 & 0.616 \\
\hline SIGMAM & 0.179 & 0.435 & 0.440 & 1.000 & 0.498 & 0.486 & 0.460 & 0.507 \\
\hline DELTAM & -0.107 & 0.675 & 0.611 & 0.498 & 1.000 & 0.784 & 0.647 & 0.547 \\
\hline ETAM & -0.069 & 0.717 & 0.733 & 0.486 & 0.784 & 1.000 & 0.751 & 0.685 \\
\hline DELTA1M & -0.106 & 0.670 & 0.695 & 0.460 & 0.647 & 0.751 & 1.000 & 0.710 \\
\hline DELTA3M & 0.055 & 0.571 & 0.616 & 0.507 & 0.547 & 0.685 & 0.710 & 1.000 \\
\hline SIGMA1M & 0.074 & 0.474 & 0.425 & 0.664 & 0.569 & 0.541 & 0.615 & 0.624 \\
\hline SP5M & -0.023 & 0.667 & 0.676 & 0.563 & 0.678 & 0.716 & 0.786 & 0.731 \\
\hline IPM & 0.050 & -0.164 & -0.168 & -0.029 & -0.153 & -0.141 & -0.110 & -0.101 \\
\hline SPM & 0.057 & -0.152 & $-0.168 \mathrm{SCl}$ & -0.018 & -0.178 & -0.153 & -0.113 & -0.134 \\
\hline PPM & 0.010 & -0.143 & -0.136 & -0.051 & -0.152 & -0.144 & -0.110 & -0.118 \\
\hline ACADM & 0.011 & -0.033 & -0.067 & -0.126 & -0.096 & -0.094 & -0.097 & -0.106 \\
\hline STATM & 0.069 & -0.112 & -0.132 & -0.013 & -0.118 & -0.109 & -0.108 & -0.121 \\
\hline ABERM & 0.136 & 0.242 & 0.164 & 0.501 & 0.335 & 0.280 & 0.302 & 0.336 \\
\hline Code & SIGMA1M & SP5M & IPM & SPM & PPM & ACADM & STATM & ABERM \\
\hline EPSM & 0.074 & -0.023 & 0.050 & 0.057 & 0.010 & 0.011 & 0.069 & 0.136 \\
\hline HIM & 0.474 & 0.667 & -0.164 & -0.152 & -0.143 & -0.033 & -0.112 & 0.242 \\
\hline ALFAM & 0.425 & 0.676 & -0.168 & -0.168 & -0.136 & -0.067 & -0.132 & 0.164 \\
\hline SIGMAM & 0.664 & 0.563 & -0.029 & -0.018 & $-0.511 b$ & -0.126 & -0.013 & 0.501 \\
\hline DELTAM & 0.569 & 0.678 & -0.153 & -0.178 & -0.152 & -0.096 & -0.118 & 0.335 \\
\hline ETAM & 0.541 & 0.716 & -0.141 & -0.153 & -0.144 & -0.094 & -0.109 & 0.280 \\
\hline DELTAIM & 0.615 & 0.786 & -0.110 & -0.113 & -0.110 & -0.097 & -0.108 & 0.302 \\
\hline DELTA3M & 0.624 & 0.731 & -0.101 & -0.134 & -0.118 & -0.106 & -0.121 & 0.336 \\
\hline SIGMAIM & 1.000 & 0.719 & -0.075 & -0.077 & -0.083 & -0.148 & -0.054 & 0.598 \\
\hline SP5M & 0.719 & 1.000 & -0.108 & -0.110 & -0.114 & -0.110 & -0.092 & 0.415 \\
\hline IPM & -0.075 & -0.108 & 1.000 & 0.493 & 0.399 & 0.185 & 0.264 & 0.024 \\
\hline SPM & -0.077 & -0.110 & 0.493 & 1.000 & 0.377 & 0.260 & 0.284 & 0.012 \\
\hline PPM & -0.083 & -0.114 & 0.399 & 0.377 & 1.000 & 0.131 & 0.257 & 0.012 \\
\hline USPM & -0.148 & -0.110 & 0.185 & 0.260 & 0.131 & 1.000 & 0.133 & -0.234 \\
\hline STATM & -0.054 & -0.092 & 0.264 & 0.284 & 0.257 & 0.133 & 1.000 & 0.066 \\
\hline ABERM & 0.598 & 0.415 & 0.024 & 0.012 & 0.012 & -0.234 & 0.066 & 1.000 \\
\hline
\end{tabular}


D. Popovic et al.

Table 3. Intercorrelations of variables in the sample of female participants.

\begin{tabular}{|c|c|c|c|c|c|c|c|c|}
\hline Code & EPSF & CHIF & ALPHAF & SIGMAF & DELTAF & ETAF & DELTA1F & DELTA3F \\
\hline EPSF & 1.000 & -0.140 & -0.231 & 0.284 & -0.171 & -0.114 & -0.203 & 0.069 \\
\hline CHIF & -0.140 & 1.000 & 0.757 & 0.422 & 0.686 & 0.764 & 0.724 & 0.578 \\
\hline ALPHAF & -0.231 & 0.757 & 1.000 & 0.375 & 0.630 & 0.755 & 0.707 & 0.557 \\
\hline SIGMAF & 0.284 & 0.422 & 0.375 & 1.000 & 0.417 & 0.457 & 0.383 & 0.462 \\
\hline DELTAF & -0.171 & 0.686 & 0.630 & 0.417 & 1.000 & 0.715 & 0.684 & 0.516 \\
\hline ETAF & -0.114 & 0.764 & 0.755 & 0.457 & 0.715 & 1.000 & 0.790 & 0.710 \\
\hline DELTAIF & -0.203 & 0.724 & 0.707 & 0.383 & 0.684 & 0.790 & 1.000 & 0.644 \\
\hline DELTA3F & 0.069 & 0.578 & 0.557 & 0.462 & 0.516 & 0.710 & 0.644 & 1.000 \\
\hline SIGMAIF & 0.101 & 0.448 & 0.361 & 0.572 & 0.544 & 0.495 & 0.536 & 0.538 \\
\hline SP5F & -0.093 & 0.650 & 0.638 & 0.496 & 0.698 & 0.715 & 0.754 & 0.615 \\
\hline IPF & 0.028 & -0.079 & -0.097 & 0.006 & -0.105 & -0.080 & -0.076 & -0.046 \\
\hline SPF & 0.080 & -0.193 & -0.188 & 0.023 & -0.257 & -0.178 & -0.186 & -0.101 \\
\hline PPF & 0.014 & -0.184 & -0.205 & -0.087 & -0.227 & -0.219 & -0.188 & -0.154 \\
\hline ACADF & -0.059 & -0.153 & -0.107 & -0.133 & -0.191 & -0.141 & -0.150 & -0.155 \\
\hline STATF & 0.116 & -0.149 & -0.201 & 0.017 & -0.178 & -0.133 & -0.166 & -0.117 \\
\hline ABERF & 0.251 & 0.231 & 0.108 & 0.449 & 0.245 & 0.220 & 0.242 & 0.256 \\
\hline Code & SIGMAIF & SP5F & IPF & SPF & PPF & ACADF & STATF & ABERF \\
\hline EPSF & 0.101 & -0.093 & 0.028 & 0.080 & 0.014 & -0.059 & 0.116 & 0.251 \\
\hline CHIF & 0.448 & 0.650 & -0.079 & -0.193 & -0.184 & -0.153 & -0.149 & 0.231 \\
\hline ALPHAF & 0.361 & 0.638 & -0.097 & -0.188 & -0.205 & -0.107 & -0.201 & 0.108 \\
\hline SIGMAF & 0.572 & 0.496 & 0.006 & 0.023 & -0.087 & -0.133 & 0.017 & 0.449 \\
\hline DELTAF & 0.544 & 0.698 & -0.105 & -0.257 & -0.227 & -0.191 & -0.178 & 0.245 \\
\hline ETAF & 0.495 & 0.715 & -0.080 & -0.178 & -0.219 & -0.141 & -0.133 & 0.220 \\
\hline DELTA1F & 0.536 & 0.754 & -0.076 & -0.186 & -0.188 & -0.150 & -0.166 & 0.242 \\
\hline DELTA3F & 0.538 & 0.615 & -0.046 & -0.101 & -0.154 & -0.155 & -0.117 & 0.256 \\
\hline SIGMA1F & 1.000 & 0.663 & 0.003 & -0.108 & -0.120 & -0.204 & -0.069 & 0.453 \\
\hline SP5F & 0.663 & 1.000 & -0.025 & -0.109 & -0.163 & -0.130 & -0.104 & 0.326 \\
\hline IPF & 0.003 & -0.025 & 1.000 & 0.425 & 0.453 & 0.174 & 0.206 & 0.073 \\
\hline SPF & -0.108 & -0.109 & 0.425 & 1.000 & 0.455 & 0.311 & 0.322 & 0.069 \\
\hline PPF & -0.120 & -0.163 & 0.453 & 0.455 & 1.000 & 0.237 & 0.265 & 0.056 \\
\hline ACADF & -0.204 & -0.130 & 0.174 & 0.311 & 0.237 & 1.000 & 0.178 & -0.258 \\
\hline STATF & -0.069 & -0.104 & 0.206 & 0.322 & 0.265 & 0.178 & 1.000 & 0.112 \\
\hline ABERF & 0.453 & 0.326 & 0.073 & 0.069 & 0.056 & -0.258 & 0.112 & 1.000 \\
\hline
\end{tabular}


Table 4. Correlation differences.

\begin{tabular}{|c|c|c|c|c|c|c|c|c|}
\hline Code & EPSF & CHIF & ALPHAF & SIGMAF & DELTAF & ETAF & DELTA1F & DELTA3F \\
\hline EPSM & 0.000 & 0.026 & 0.103 & -0.105 & 0.064 & 0.045 & 0.097 & -0.014 \\
\hline CHIM & 0.026 & 0.000 & -0.041 & 0.013 & -0.011 & -0.047 & -0.054 & -0.006 \\
\hline ALPHAM & 0.103 & -0.041 & 0.000 & 0.064 & -0.019 & -0.021 & -0.013 & 0.059 \\
\hline SIGMAM & -0.105 & 0.013 & 0.064 & 0.000 & 0.082 & 0.029 & 0.078 & 0.045 \\
\hline DELTAM & 0.064 & -0.011 & -0.019 & 0.082 & 0.000 & 0.070 & -0.037 & 0.031 \\
\hline ETAM & 0.045 & -0.047 & -0.021 & 0.029 & 0.070 & 0.000 & -0.039 & -0.025 \\
\hline DELTA1M & 0.097 & -0.054 & -0.013 & 0.078 & -0.037 & -0.039 & 0.000 & 0.066 \\
\hline DELTA3M & -0.014 & -0.006 & 0.059 & 0.045 & 0.031 & -0.025 & 0.066 & 0.000 \\
\hline SIGMA1M & -0.028 & 0.026 & 0.064 & 0.092 & 0.025 & 0.046 & 0.079 & 0.085 \\
\hline SP5M & 0.070 & 0.017 & 0.038 & 0.067 & -0.020 & 0.000 & 0.032 & 0.116 \\
\hline IPM & 0.022 & -0.085 & -0.071 & -0.035 & -0.047 & -0.061 & -0.035 & -0.055 \\
\hline SPM & -0.023 & 0.041 & 0.020 & -0.041 & 0.079 & 0.025 & 0.073 & -0.033 \\
\hline PPM & -0.004 & 0.041 & 0.069 & 0.036 & 0.075 & 0.075 & 0.078 & 0.036 \\
\hline ACADM & 0.070 & 0.120 & 0.040 & 0.007 & 0.095 & 0.047 & 0.054 & 0.050 \\
\hline STATM & -0.047 & 0.037 & 0.069 & -0.030 & 0.060 & 0.023 & 0.058 & -0.005 \\
\hline ABERM & -0.114 & 0.010 & 0.056 & 0.052 & 0.090 & 0.060 & 0.060 & 0.080 \\
\hline Code & SIGMA1F & SP5F & IPF & SPF & PPF & ACADF & STATF & ABERF \\
\hline EPSM & -0.028 & 0.070 & 0.022 & -0.023 & -0.004 & 0.070 & -0.047 & -0.114 \\
\hline CHIM & 0.026 & 0.017 & -0.085 & 0.041 & 0.041 & 0.120 & 0.037 & 0.010 \\
\hline ALPHAM & 0.064 & 0.038 & -0.071 & 0.020 & 0.069 & 0.040 & 0.069 & 0.056 \\
\hline SIGMAM & 0.092 & 0.067 & -0.035 & -0.041 & 0.036 & 0.007 & -0.030 & 0.052 \\
\hline DELTAM & 0.025 & -0.020 & -0.047 & 0.079 & 0.075 & 0.095 & 0.060 & 0.090 \\
\hline ETAM & 0.046 & 0.000 & -0.061 & 0.025 & 0.075 & 0.047 & 0.023 & 0.060 \\
\hline DELTA1M & 0.079 & 0.032 & -0.035 & 0.073 & 0.078 & 0.054 & 0.058 & 0.060 \\
\hline DELTA3M & 0.085 & 0.116 & -0.055 & -0.033 & 0.036 & 0.050 & -0.005 & 0.080 \\
\hline SIGMA1M & 0.000 & 0.056 & -0.079 & 0.031 & 0.038 & 0.056 & 0.015 & 0.145 \\
\hline SP5M & 0.056 & 0.000 & -0.083 & -0.001 & 0.050 & 0.020 & 0.012 & 0.089 \\
\hline IPM & -0.079 & -0.083 & 0.000 & 0.068 & -0.054 & 0.011 & 0.058 & -0.049 \\
\hline SPM & 0.031 & -0.001 & 0.068 & 0.000 & -0.079 & -0.050 & -0.038 & -0.058 \\
\hline PPM & 0.038 & 0.050 & -0.054 & -0.079 & 0.000 & -0.106 & -0.009 & -0.044 \\
\hline ACADM & 0.056 & 0.020 & 0.011 & -0.050 & -0.106 & 0.000 & -0.045 & 0.024 \\
\hline STATM & 0.015 & 0.012 & 0.058 & -0.038 & -0.009 & -0.045 & 0.000 & -0.046 \\
\hline ABERM & 0.145 & 0.089 & -0.049 & -0.058 & -0.044 & 0.024 & -0.046 & 0.000 \\
\hline
\end{tabular}


Table 5. Results of the tests of differences of correlation matrices.

\begin{tabular}{ccc}
\hline Criterion & $\mathrm{X}$ & $\mathrm{P}$ \\
\hline Criterion of least squares & 1067.327 & 0.00 \\
Criterion of maximal likelihood & 1041.561 & 0.00 \\
Schoenemann's criterion & 818.280 & 0.00 \\
Krzanowski's criterion & 3542.705 & 0.00 \\
Lawley-Rippe's test & 834.789 & 0.00 \\
Hadžigalic's test & 793.500 & 0.00 \\
\hline
\end{tabular}

studies, among other things, have shown that the degree of cerebral lateralization is less in women, testosterone and cortical amines modulate conative functions essentially differently in men and women, the volume of zones in the prefrontal cortex which have functions of planning and decision-making, of control of subcortical centers are considerably larger in men, the relative size of the corpus calosum is much larger in women, the zone in which sequential processing of information takes place is significantly more developed in women, as well as many other, less noticeable though not necessarily less important, differences which clearly show that male and female brains are organized differently. What is important to understand is that in order to avoid misunderstandings, differently does not mean better or worse; differently simply means differently, and whether these differences are favorable or unfavorable to one or the other gender depends on the objective, mainly social circumstances, and, in a large degree, on the dominant value system in a period of social, including economic, development.

The fact that psychological space of women differs from men`s psychological space has a number of very significant consequences. The first is justification of quantitative comparison of cognitive and conative functions of participants of both sexes. Because cognitive and conative factors of the same name do not, apparently, have identical psychological content in men`s and women`s psychological spaces, but the important question is what actually the quantitative differences obtained through assessment of these factors mean. The second consequence is the sensitivity of male and female brains to pedagogical, therapeutic or punitive treatment. As things now stand, the female brain is probably more sensitive to all exogenous influences, but in any case, it is certain that whatever treatment that is suitable for the male brain does not have to be suitable for the female brain. The third consequence is technical in nature, but not unimportant, and because of structural differences, results in cognitive and conative tests do not have the same meaning in men and women, so at least the norms for these tests should be differentiated by gender.

\section{Conclusion}

Finally, it should be warned that the differences in the configuration of psychological space are obtained under a linear model for assessing their correlations. However, there are many indications that the relations of cognitive and especially conative factors are not linear, and their cross-relations are not linear either [2] [19]. Therefore, differences in the configuration of psychological spaces of men and women should be continued under different nonlinear models for assessing relations of cognitive and conative factors.

\section{References}

[1] Hosek, A. and Momirovic, K. (1999) Problem of True Association of Conative Factors in Sanctioned Criminals. Psychology and Social Upheavals, Book of Abstracts, Serbian Psychological Society, Belgrade, 28-29.

[2] Hosek, A. and Momirovic, K. (1999) Sexual Dimorphism in Cognitive and Conative Spaces. 5th Conference "Empirical Research in Psychology”, Book of Abstracts, Belgrade, 17-18 July 1999, 17-18.

[3] Kansaku, K. and Kitazawa, S. (2001) Imaging Studies on Sex Differences in the Lateralization of Language. Neuroscience Research, 41, 333-337. http://dx.doi.org/10.1016/S0168-0102(01)00292-9

[4] Momirovic, K. and Hosek, A. (2000) On Differences in Psychosomatic Disorders between Young Men and Women. Gazette of Anthropological Society of Yugoslavia, 35, 75-80.

[5] Momirovic, K. (2003) Classification by Neural Networks in the Analysis of Structural Differences. In: Momirovic, K. 
and Popovic, D., Eds., Construction and Application of Taxonomic Neural Networks, University of Pristina, Leposavic, 113-134.

[6] Hosek, A., Momirovic, K. and Nikitjuk, B.A. (1988) Structural Differences in Relations of Morphological Characteristics and Intellectual Abilities between Men and Women. Kinesiology, 20, 89-92.

[7] Momirovic, K., et al. (1988) Methods, Algorithms and Programs for the Analysis of Quantitative and Qualitative Changes. Institute of Kinesiology, Zagreb.

[8] Momirovic, K., Wolf, B. and Dzamonja, Z. (1992) Cybernetic Battery of Conative Tests. Applied Psychology Center, Belgrade.

[9] Momirovic, K., Horga, S. and Bosnar, K. (1982b) Contribution to the Formation of a Cybernetic Model of the Structure of Conative Factors. Kinesiology, 14, 83-108.

[10] Wolf, B., Momirovic, K. and Dzamonja, Z. (1992) COG 3: Intelligence Test Battery. Applied Psychology Center,. Belgrade.

[11] Hosek, A. (1994) Proposal of Procedures to Assess the Efficiency of Socialization Process. Journal of Clinical Psychology and Social Pathology, 1, 1-2:229-250.

[12] Hosek, A., Momirovic, K. and Jovanovic, S. (2001) Contribution to the Analysis of Sexual Dimorphism in Conative Space. Psychology, 34, 121-138.

[13] Momirovic, D., Wolf, B. and Popovic, D. (1999) Introduction to the Theory of Measurement and Internal Metric Properties of Composite Measurement Instruments. (Monograph) Multidisciplinary Research Center, Faculty of Physical Education, Pristina.

[14] Popovic, D. (1993) Programs and Subprograms for the Analysis of Quantitative Modifications. (Monography) Multidisciplinary Research Center, Faculty of Physical Education, Pristina.

[15] Kimura, M. (1992) Sex Differences in the Brain. Scientific American, 267, 81-87. http://dx.doi.org/10.1038/scientificamerican0992-118

[16] Kimura, D. (1983) Sex Differences in Cerebral Organization for Speech and Praxic Functions. Canadian Psychology, 32, 19-35. http://dx.doi.org/10.1037/h0080696

[17] Kimura, D. (1996) Sex, Sexual Orientation and Sex Hormones Influence Human Cognitive Function. Current Opinion in Neurobiology, 6, 259-263. http://dx.doi.org/10.1016/S0959-4388(96)80081-X

[18] Momirovic, K., Horga, S. and Bosnar, K. (1982) Cybernetic Model of Cognitive Functioning: Attempted Synthesis of Some Theories of the Structure of Cognitive Abilities. Kinesiology, 14, 63-82.

[19] Zaidel, D.W. (2002) Review of Sex and Cognition by Doreen Kimura. Human Nature Review, 2, 239-240.

[20] Zarevski, P. (2000) The Structure and Nature of Intelligence. Naklada Slap, Zagreb. 